\title{
Characteristic of Northern Thailand Seismic Stations from Horizontal-to-Vertical Spectral Ratios (HVSR) Analysis ${ }^{\dagger}$
}

\author{
Supakorn HANSAWANGKIT and Teraphan ORNTHAMMARATH*
}

Department of Civil and Environmental Engineering, Faculty of Engineering, Mahidol University, Nakorn Pathom 73170, Thailand

('Corresponding author's e-mail: teraphan.orn@mahidol.edu)

Received: 4 June 2019, Revised: 24 January 2020, Accepted: 8 February 2020

\begin{abstract}
Several major cities in Northern Thailand are located on a sedimentary basin, which could amplify ground motion from future earthquakes as they lie along several active faults. To study the seismic response and natural periods of these basins, a Horizontal to Vertical Spectral Ratio (HVSR) for each seismic station in Northern Thailand has been proposed. Several observed ground motion from moderate to small seismic events in and around Northern Thailand were used in this analysis. Several seismometers (TSA-100S, Trillium-120, PA-23, S-13 and KS 2000) of the Department of Mineral Resources (DMR) and Thai Meteorological Department (TMD) with triaxial digital accelerometer data were used. The 3 axis digital accelerometers (2-horizontal and vertical) were converted to Fourier amplitude spectral (FAS) in order to find basin natural period by Horizontal to Vertical Spectral Ratio (HVSR). This research investigates 6 stations in Northern Thailand with at least 10 observed ground motions for each station. We found that the natural period of three stations (CRAI, PAYA and PHRA) showed strong site amplification effect at low natural period (between $0.1-0.2 \mathrm{~s}$ with an amplitude larger than 2 ). The natural period of CMMT and MHIT stations were insignificant since CMMT and MHIT were located on the rocks. Lastly, we observed long natural period for CMCA station located in Chiang Mai basin around $2.50 \mathrm{~s}$ with an amplitude larger than 3. Furthermore, the computed site natural periods were compared with the average top $30 \mathrm{~m}$ shear wave velocity $\left(\mathrm{Vs}_{30}\right)$ based on the data from the Shuttle Radar Topography Mission (SRTM) and Multichannel Analysis of Surface Wave (MASW) to find the type of soil in each area.
\end{abstract}

Keywords: Horizontal-to-vertical spectral ratio, Natural period, Seismic, Ground motion

\section{Introduction}

Earthquake is a natural disaster caused by the vibration of strong ground motion and stress accumulation reduction. The scientists cannot predict the time, place, and intensity of an earthquake. Places in Northern Thailand usually experience the vibration of strong ground motion since these places lie along the active fault Figure 1. Earthquakes can cause damage to buildings, roads, and land which are life-threatening. If an earthquake strikes in Northern Thailand, buildings will collapse because they are not designed for earthquakes according to Seismic Resistant Design of Buildings and Structures (National Standard DPT 1302).

On 11 November 2012, a large $\mathrm{M}_{\mathrm{w}}=7.8$ subduction earthquake occurred in Myanmar, which is close to the city of Shewbo, about $440 \mathrm{~km}$ away from Mae Hong Son. This earthquake was felt in northern Chiang Mai, Chiang Rai, Mae Hong Son, Lampang. On 5 May 2014 [1], a large $\mathrm{M}_{\mathrm{w}}=6.3$

${ }^{\dagger}$ Presented at the $2^{\text {nd }}$ International Symposium on Construction Innovation Research \& PhD Symposium: July 18-19, 2019. 
http://wjst.wu.ac.th

earthquake occurred in Thailand close to the city of Chiang Rai (near Mae Lao). After the earthquake, there were 700 aftershocks that were recorded. This was the most severe earthquake that has been recorded as it caused a lot of damage in 7 provinces, including Chiang Mai, Chiang Rai, Pha Yao, Nan, Phrae, Lam Pang, and Kamphaeng Phet, as well as in highrise buildings in Bangkok (at epicentral distance of $670 \mathrm{~km}$ ). The most damaged infrastructure (Chiang Rai area) was that of the non-engineered RC frames with masonry infill walls, which was not connected to other constituent. On 12 January 2018, a large $\mathrm{M}_{\mathrm{w}}=5.9$ subduction earthquake occurred in Myanmar close to the city of Pyu at a hypocentral depth of $10 \mathrm{~km}$ away from Mae Hong Son $225 \mathrm{~km}$. The earthquake was also felt in Chiang Mai. The people in the province were shocked because of the strong vibration. These three incidents made us aware of the consequences that would occur in the future.

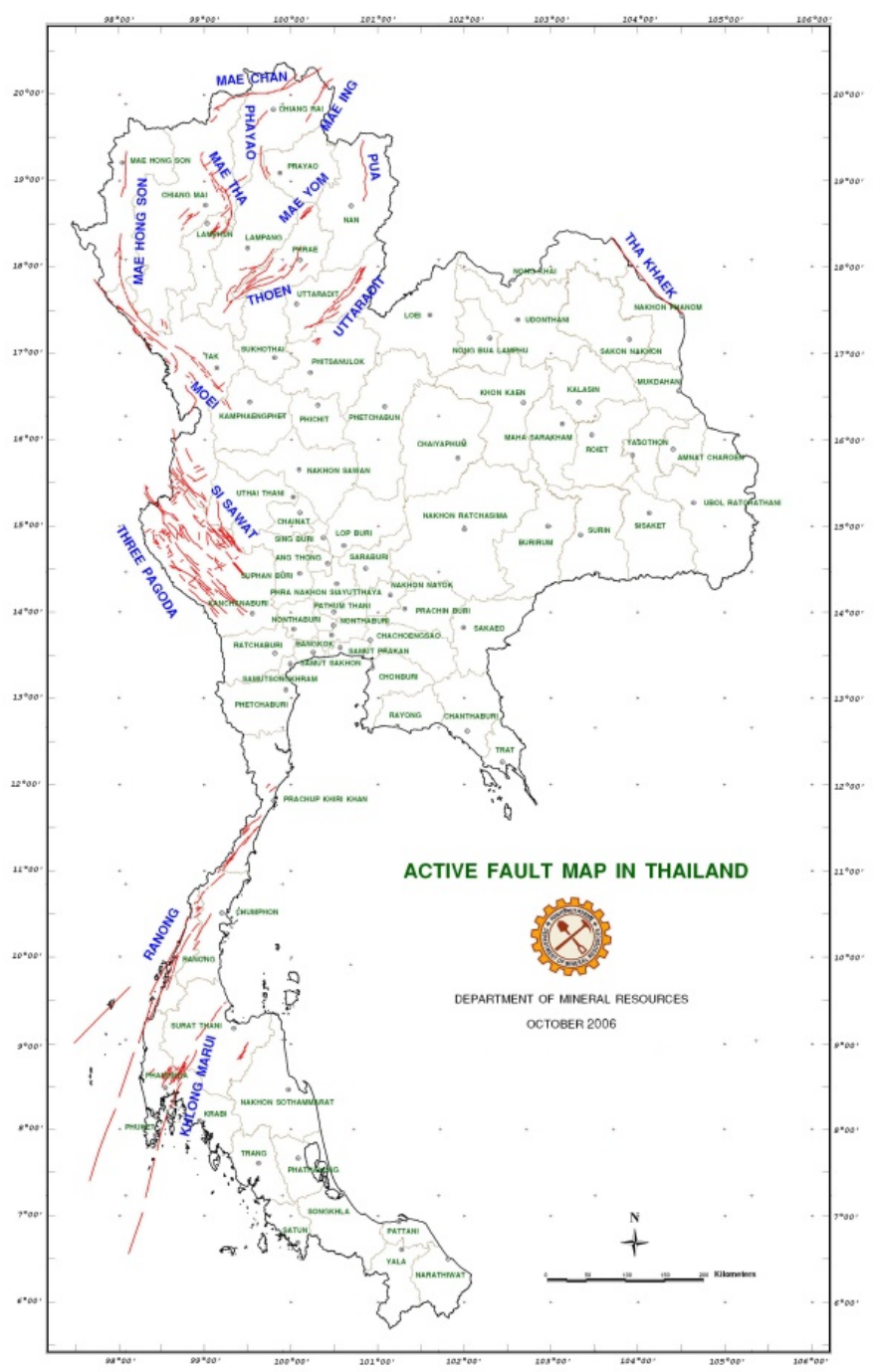

Figure 1 Active fault in Thailand from the Department of Mineral Resources (DMR). 
http://wjst.wu.ac.th

Therefore, the design of the building to withstand earthquakes is important in order to reduce the loss of life and damage to properties in the future. This study found the predominant period and the amplification factor of soil. We could use the predominant period to design a building in order to withstand earthquakes. Data from 2011 to 2018 were obtained from the stations in Northern Thailand (6 stations). It has an approximate of 10 incidents for every station (6 stations). This was processed by using Horizontal to Vertical Spectral Ratio (HVSR) [2,3]. The results of this study showed that the HVSR method could be an effective method to improve seismic design code.

\section{Materials and methods}

In this paper, we were interested in a particular area of Northern Thailand. This area was the most affected in the country. We collected the data all from 6 stations (CMCA, CMMT, CRAI, PAYA, PHRA, and MHIT) in Chaing Mai, Chaing Rai, Mae Hong Son, Phrae, and Phayao shown in Figure 2.

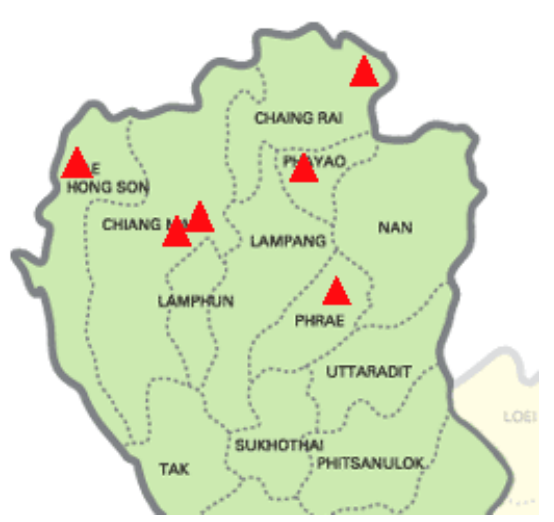

(a)

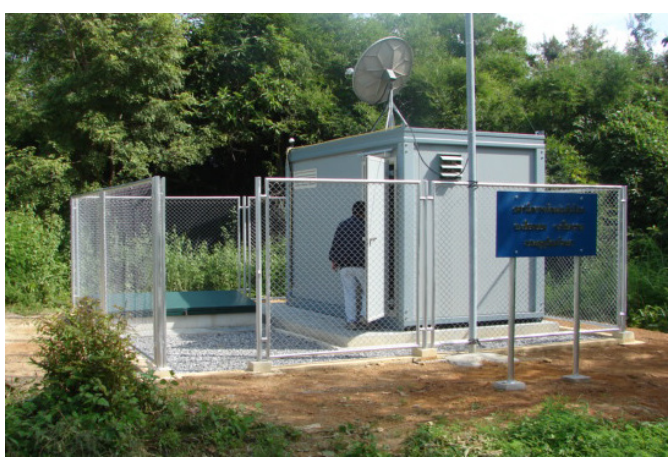

(b)

Figure 2 (a) Map of Northern Thailand with seismic station. (b) CRAI station was installed near Huai Chang reservoir.

Several observed ground motion from moderate to small seismic events in and around Northern Thailand were used in this analysis. Several seismometers (TSA-100S, Trillium-120, PA-23, S-13 and KS2000) from the Department of Mineral Resources (DMR) and Thai Meteorological Department (TMD) with triaxial digital accelerometer data were used. Thus, 72 events were selected with predicted magnitude higher than $3.5 \mathrm{M}_{\mathrm{w}}$. In this paper, we use the Horizontal to Velocity Spectrum Ratio (HVRS). This is the ratio between the Fourier amplitude spectra of the horizontal and vertical components of microtremors by Nakamura [2] show in Figure 4.

The $1^{\text {st }}$ step was to check out the noise from the raw data (2D horizontal and vertical components) in each station by signal to noise ratio (SNR) 3092-103.

[4], and only the frequencies with SNR $>3$ were used in the computation of the spectral ratio [5]. The time-series windowing was applied automatically in the preliminary study. Furthermore, the noise in a $60 \mathrm{~s}$ window was extracted to identify $1 \mathrm{~s}$ before the theoretical P-wave time arrival $\left(\mathrm{T}_{\mathrm{P}}\right)$. From the Kishida [6] approach, the signal duration $\left(\mathrm{D}_{\mathrm{S}}\right)$ was determined with respect to source and propagation terms, with a minimum duration of $10 \mathrm{~s}$. Accordingly, the total signal length can be obtained between $T_{P}$ and $T_{P}+D_{s}$ show in Figure 3. The $2^{\text {nd }}$ step was to examine the frequencies of each axis, but the recorded motion was the time domain and it was difficult to find the maximum frequency. Therefore, the time domain should be converted into the frequency domain. Signals were converted from the time domain into the frequency domain, which was usually used by fast Fourier Transform (FFT) [7]. We chose the signal between $10-60 \mathrm{~s}$ to compare the dissimilarity in frequencies of signals. Fourier acceleration 
http://wjst.wu.ac.th

spectra (FAS) were computed and smoothed according to the Konno and Ohmachi [8] smoothing with parameter $b=40$. Then, FAS were resampled for a 500 logarithmically spaced sample frequency vector between 0.1 and $50 \mathrm{~Hz}$. The last step before calculating the HVSR was to filter out the unwanted frequencies by using the Butterworth filter.

For HVSR computations, 72 events were used regardless of the location of the epicentral. The average of the HVSR was calculated if there were spectrum ratios for three components with a good SNR $(\mathrm{SNR}>3)$. This process was performed at each frequency independently.

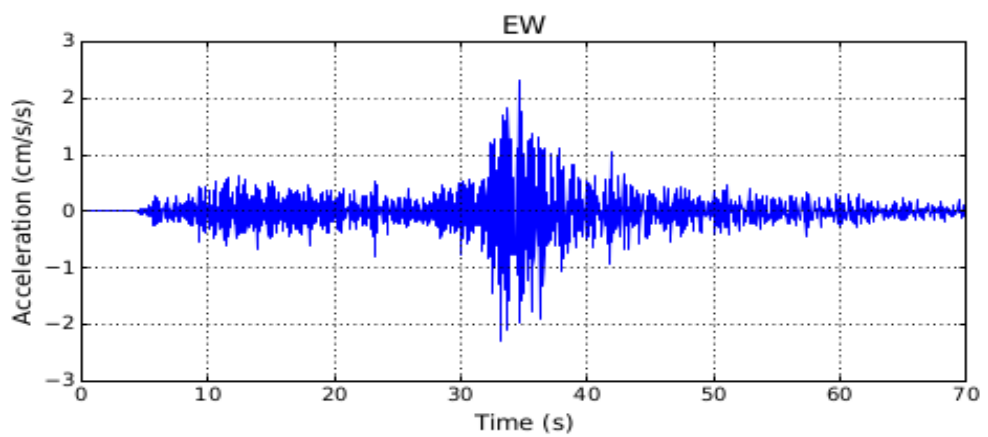

Figure 3 The acceleration graph (East-west) of Chiang Rai station on 22 February 2011 after checking the SNR and finding the signal duration.
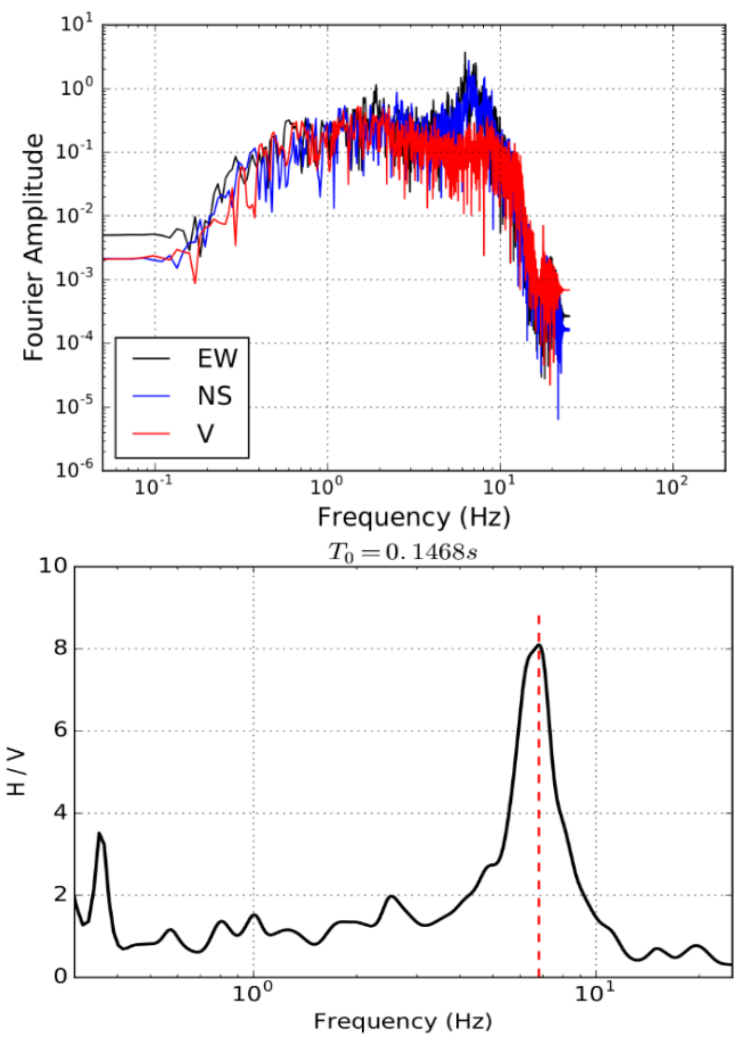

Figure 4 The graph Fourier transform (top) and HVSR curve (bottom) of Chiang Rai station on 22 February 2011. 
http://wjst.wu.ac.th

\section{Results and discussion}

Figure 5 illustrates the correlation between the magntidue and distance of the earthquake epicenter from 6 stations; CRAI, PAYA, CMCA, CMMT, PHRA and MHIT station. The information was collected from 2011 to 2018 as following; 10 events had been recorded from CRAI station located near Huai Chang reservoir. For PAYA and PHRA stations, the data was collected from 12 and 14 cases each near Mae Puem and Mae Song reservoir, respectively. Chiang Mai has 2 stations; CMMT and CMCA, which are close to Doi Suthep and Chiang Mai International Airport recorded 12 and 5 events occurring respectively. Finally, MHIT station which is located near Mae Hong Son Immigration accumulated the information from 19 data. Additionally, data from CMCA was less than the others due to the time availability as it was recorded since 2018 only.

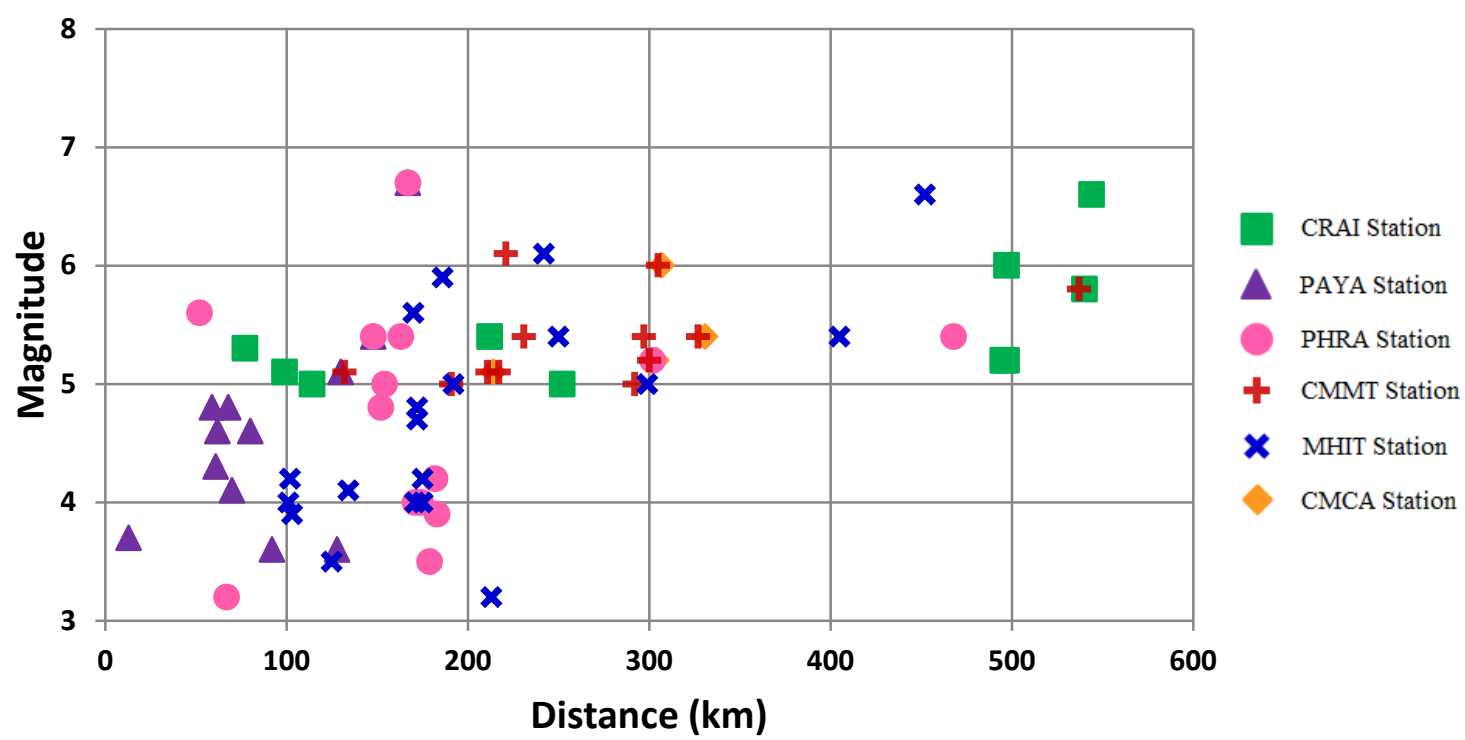

Figure 5 Showing the relationship of magnitude and distance of the earthquake.

The peak of the predominant period and natural frequency from each station were represented by HVSR curve in Figure 6. Based on the Shuttle Radar Topography Mission (SRTM) [9], the average 30 shear wave velocity in Thailand was shown in Figure 7. This data was used to further classify soil information of selected seismic station in current study. Furthermore, $\mathrm{Vs}_{30}$ availablity was directly measured by Multichannel Analysis of Surface Wave (MASW) [10]. The data is shown in Table 1. From Figure 6, seismic stations in current study could be classified in to 3 types; the high-frequency (CRAI, PAYA and PHRA stations), low-frequency (CMCA station) range, and no site amplification effect (CMMT and MHIT stations). 


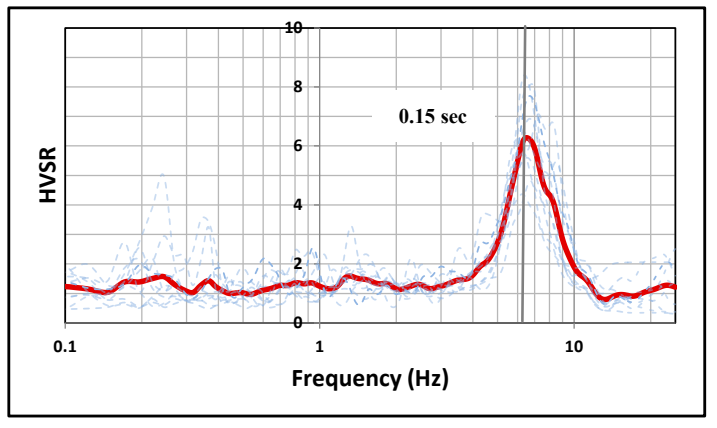

(A) CRAI Station

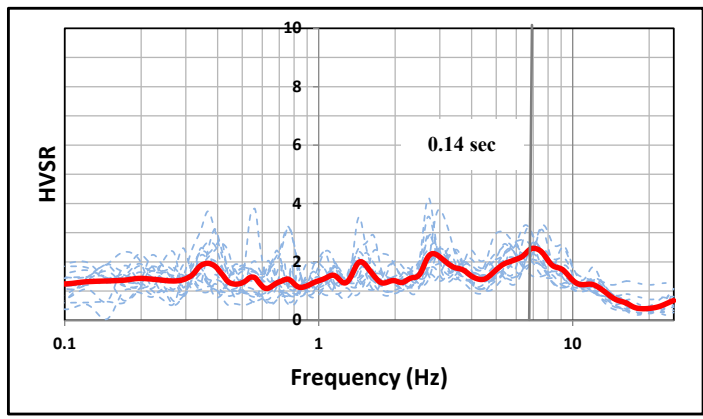

(C) PHRA Station

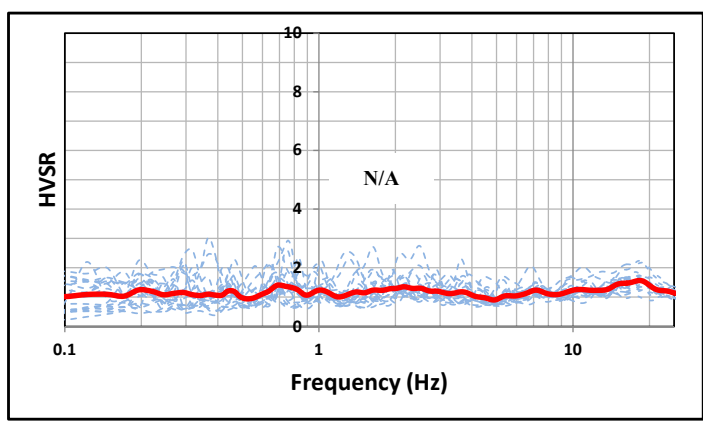

(E) MHIT Station

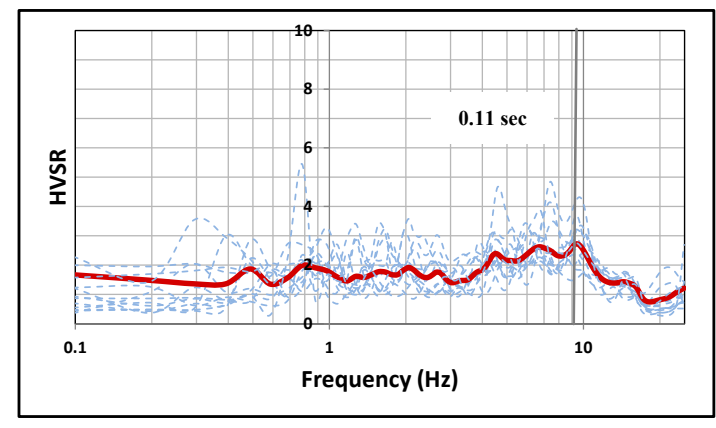

(B) PAYA Station

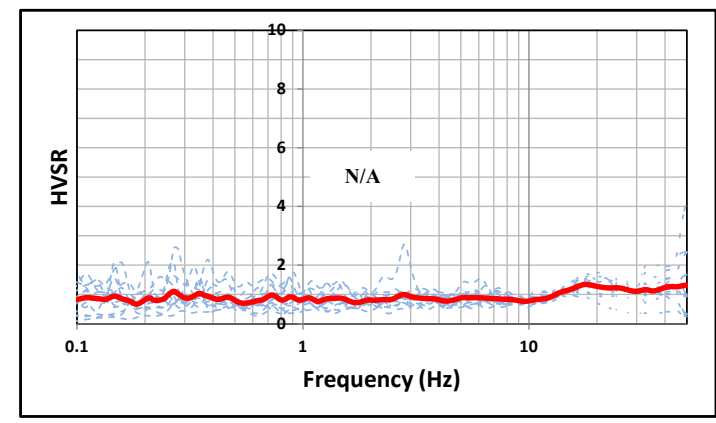

(D) CMMT Station

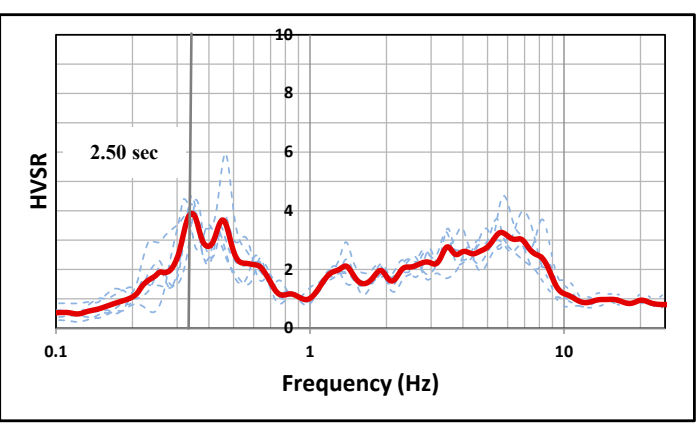

(F) CMMA Station

Figure 6 HVSR analysis of each station. 


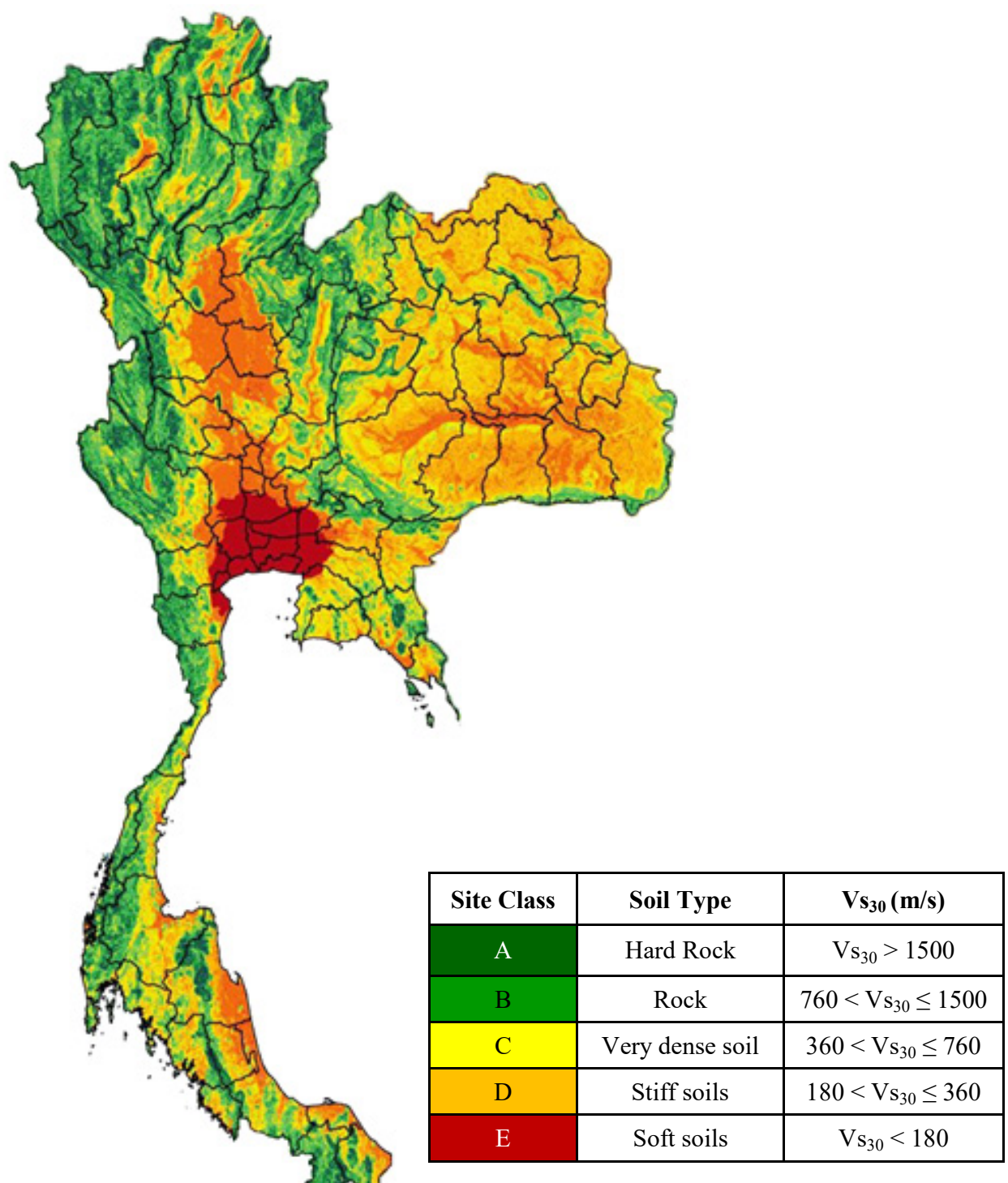

Figure 7 Average shear velocity in the top $30 \mathrm{~m}\left(\mathrm{Vs}_{30}\right)$ in Thailand. 
http://wjst.wu.ac.th

Table 1 Compare average shear velocity $\left(\mathrm{Vs}_{30}\right)$ between SRTM and MASW.

\begin{tabular}{ccc}
\hline \multirow{2}{*}{ Station } & \multicolumn{2}{c}{$\mathbf{V s}_{\mathbf{3 0}} \mathbf{( m / s )}$} \\
\cline { 2 - 3 } & SRTM & MASW \\
\hline CRAI & 485 & 362 \\
PAYA & 553 & 443 \\
PHRA & 459 & 499 \\
CMCA & 258 & 392 \\
CMMT & 821 & - \\
MHIT & 792 & - \\
\hline
\end{tabular}

*CMCA station was located on a sedimentary basin

**CMMT and MHIT station were located on a rock site

From Figure 6 a, b, and c, CRAI, PAYA and PHRA stations displayed the noticeable peak at high frequency between 5 to $10 \mathrm{~Hz}$, low period between $0.1-0.2 \mathrm{~s}$. PAYA and PHRA stations had an amplitude larger than 2. CRAI had clear peak amplitude larger than 5 which could be attributed to the fact that CRAI stations are located near the Mekong river, where site amplification effect could be clearly observed. The $\mathrm{Vs}_{30}$ of SRTM and MASW showed that PAYA and PHRA were located at very dense soil as it has an impact on the high-frequency range or low period unlike the soft soil that affects only the lowfrequency and high period. Among the seismic station in current study, the CMCA station had the lowest natural frequency between $0.3-0.5 \mathrm{~Hz}$ and amplitude larger than 3. The $\mathrm{Vs}_{30}$ of SRTM and MASW at station CMCA was $258 \mathrm{~m} / \mathrm{s}$ (stiff soil) and $392 \mathrm{~m} / \mathrm{s}$ (very dense soil) respectively. If we look at the fault map of northern Thailand, it can be seen that the station was located in the sediment basin. In addition, we already checked at the active fault map of northern Thailand and see that this station is located in the area of sediment basin. From the HVSR curves of CMMT and MHIT station, the data is not significant and the amplitude is less than 2 since CMMT and MHIT are located on the rocks. From Figure 7, most of the Northern areas had soil types of B and C, while some areas had also soil type D.

\section{Conclusions}

In this study, we took advantage of the earthquake ground motion records of the DMR and TMD stations deployed since 2011 in northern Thailand to assess site effects in the Northern stations. We applied the HVSR method to find the predominant period of each seismic station. We identified a noticeably different behavior among the stations on rock, very dense soil, and stiff soil. For all the stations located on a very dense soil site, HVSR results from these stations showed consistent high natural frequencies. All spectral ratios displayed a distinct high-frequency peak around $5-10 \mathrm{~Hz}$ (amplitudes larger than 2). For the CMCA station located on a stiff soil site, HVSR presented a distinct low-frequency peak around $0.3-0.5 \mathrm{~Hz}$ (amplitudes larger than 3). For the stations located on a rock site, HVSR analysis showed no site amplification effects. All spectrum ratios for rock sites did not show outstanding frequencies (amplitudes lower than 2). The result of the site period obtained by HVSR was consistent with available soil information. Based on current analysis, HVSR analysis results clearly showed that CMCA station could be classified as soil type D since Chiang Mai is located within the 'soil basins, where several medium to high rise buildings are located, with a unique low-frequency site period. The areas located on the stiff soil and rock conditions have site periods within high-frequency range. In conclusion, predominant site periods obtained by HVSR method in the current study could provide the first order approximation of possible soil amplification for several urban cities in Northern Thailand. 
http://wjst.wu.ac.th

Ongoing seismic monitoring will consider to be the important issue to further determine site amplification for several other cities in Northern Thailand to avoid seismic damage from future earthquakes.

\section{Acknowledgements}

I am sincerely grateful to my advisor, Assistant Professor Dr. Teraphan Ornthammarath, who gives the guidance and advice rendered throughout the process of this paper. This research was supported by the staff at the Department of Civil and Environmental Engineering, Faculty of Engineering, Mahidol University, Thailand in conducting the research.

\section{References}

[1] O Teraphan and W Pennung. 5 May $2014 \mathrm{M}_{\mathrm{W}}$ 6.1 Mae Lao (Northern Thailand) earthquake: Interpretations of recorded ground motion and structural damage. Earthquake Spectra 2016; 32, 1209-38.

[2] Y Nakamura. A method for dynamic characteristics estimations of subsurface using microtremors on the ground surface. Q. Rep. Railway Tech. 1989; 30, 25-33.

[3] H Kawase, S Matsushima, T Satoh and F J Sánchez-Sesma. Applicability of theoretical horizontalto-vertical ratio of microtremors based on the diffuse field concept to previously observed data. Bull. Seismol. Soc. Am. 2015; 105, 3092-103.

[4] K Robert, R Pall and T J Mulligan. Definition of signal-to-noise ratio and its critical role in splitbeam measurements. ICES J. Mar. Sci. 2005; 62, 123-30.

[5] L Aurore, C Françoise, F Luis, A Alexandra, A Victor, P Naya and R Mario. Low-frequency seismic amplification in the Quito Basin (Ecuador) revealed by Accelerometric Recordings of the RENAC Network. Bull. Seismol. Soc. Am. 2017; 107, 2917-26.

[6] K Tadahiro, K Olga-Joan, D Robert and S Walter. Semi-Automated Procedure for Windowing Time Series and Computing Fourier Amplitude Spectra for the NGA-West2 Database. PEER Report No. 2016/02. Pacific Earthquake Engineering Research Center Headquarters at the University of California, Berkeley, 2016, p. 1-13.

[7] Z Udo. DAFX Digital Audio Effects. $2^{\text {nd }}$ ed. John Wiley \& Sons, Chichester, West Susex, 2011, p. $20-43$.

[8] K Konno and T Ohmachi. Ground-motion characteristics estimated axial spectral ratio between horizontal and vertical components of microtremor. Bull. Seismol. Soc. Am. 1998; 88, 228-41.

[9] T Allen and D Wald. On the use of high-resolution topographic data as a proxy for seismic site conditions $\left(\mathrm{Vs}_{30}\right)$. Bull. Seismol. Soc. Am. 2009; 99, 935-43.

[10] P Passakorn, W Pennung, C Chatpan, W Burin, P Sumalee and P Patinya. Analysis of Recorded Earthquake Ground motions in Thailand for Applications in Earthquake Engineering and Seismology. Final Report. Thei Thai Research Fund, Thailand, 2014, p. 1-330. 